\title{
Developing Sound Knowledge of Basic Science Concepts in Children Using Flipped Classroom: A case of simple repeated measures
}

\author{
Christian Sunday Ugwuanyi ${ }^{1}$ (D)
}

Received: 21 June 2021 / Accepted: 2 December 2021 / Published online: 7 January 2022

(c) The Author(s), under exclusive licence to Springer Science+Business Media, LLC, part of Springer Nature 2022

\begin{abstract}
Due to the advent of coronavirus disease in most nations throughout the world, the manner of education altered from traditional face-to-face to remote or online teaching. As a result, the new normal necessitates the adoption of an online teaching and learning platform for all levels of education. The study tested the effectiveness of a flipped classroom instructional technique on children's development of sound knowledge of Basic Science concepts. Thirty-one primary three children took part in the treatment session, which was conducted using a simple repeated measures design. The study collected data using the Basic Science Achievement Test (BSAT), which was adequately validated and trial-tested. The children were given two distinct pretests before the treatment and two different posttests afterward. The data were analyzed using a mixed-design repeated-measures analysis of variance. The findings demonstrated that using a flipped classroom instructional technique boosted children's development of a good understanding of Basic Science significantly $(p=000)$ with an effect size of 0.953 . The implementation of a flipped classroom instructional technique in teaching and learning Basic Science was advocated as a result of these results.
\end{abstract}

Keywords Basic science $\cdot$ Children · Developing $\cdot$ Flipped classroom $\cdot$ Simple repeated measures $\cdot$ Sound knowledge

Christian Sunday Ugwuanyi

ugwuanyics@ufs.ac.za

1 School of Education Studies, Faculty of Education, University of the Free State, Bloemfontein, South Africa 


\section{Introduction}

\subsection{Statement of the problem and background to the research}

Over the years, there have been instances of pupils performing poorly in Basic Science, which is the foundation for science disciplines at higher school levels (Agboeze et al., 2020; Ugwuanyi, Ede, et al., 2020; Ugwuanyi, Gana, et al., 2020). The low performance of children on the topic has been linked to teachers' usage of traditional teaching methods. In most nations throughout the world, the manner of education has evolved from traditional face-to-face to remote or online since the outbreak of coronavirus 2019 (COVID-19). The outbreak of (COVID-19) has wreaked havoc on the educational system around the world. Since a result, many schools, particularly in affluent countries, have adopted the online style of instruction as faceto-face instruction has been put on pause to prevent the spread of COVID-19. However, most classrooms around the world appear to be dominated by lectures and textbased instruction (Chang \& Lan, 2021).

The outbreak of coronavirus illness (COVID-19) in 2019 has wreaked havoc on the educational system around the world. Since a result, many schools, particularly in affluent countries, have adopted the online style of instruction as face-to-face instruction has been put on pause to prevent the spread of COVID-19. However, most classrooms around the world appear to be dominated by lectures and textbased instruction (Chang \& Lan, 2021). There is well-documented evidence of the usefulness of the flipped classroom approach across disciplines in both K-12 and higher education, according to Chang and Lan (2021). In most countries, the flipped classroom is a well-known teaching approach for numerous science courses (Dogan et al., 2021). In a word, the flipped classroom is the inversion of traditional classroom practices (Dogan et al., 2021). The flipped classroom is a student-centered learning technique in which students conduct pre-class work to gain basic information before engaging in classroom activities (Lichvar et al., 2016). Pre-class exercises in a flipped classroom include textbook, web-based, or literature readings, as well as watching recordings of classroom lessons at their own leisure (Lichvar et al., 2016). As an innovative active learning strategy, flipped learning presents students with a variety of chances (Birgili et al., 2021).

\subsection{Review of related empirical studies}

Many recent studies have been conducted on the impact of flipped classrooms on student achievement in various subject areas, particularly science. The implementation of a flipped classroom approach increased pupils' English language skills (Chang \& Lan, 2021). The use of a flipped classroom method has a considerable favorable influence on academic attainment in Science classes (Dogan et al., 2021). In a group of high school students, Lichvar et al. (2016) discovered that using a flipped classroom is an effective and active learning technique. The adoption of a flipped classroom approach greatly increased student interest in learning modules when compared to standard teaching 
methods (Afzali \& Izadpanah, 2021; Rotellar \& Cain, 2016). Adding gaming components to a flipped classroom improved students' learning performance, motivation, and participation significantly (Ekici, 2021). When compared to other classroom models, teachers who used a flipped classroom dramatically improved students' academic attainment (Polat \& Karabatak, 2021).

Furthermore, students who took flipped courses improved their critical thinking skills substantially more than their peers who did not (Styers et al., 2018). In a study of scientific students, those who were taught using the flipped classroom method performed much better than those who were taught using the standard lecture style (Joseph et al., 2021). As a result of the flipped learning outcomes, students' performance improved dramatically (Birgili et al., 2021). Students' performance and impressions of an online open distance-learning environment improved dramatically as a result of the flipped classroom strategy (Van Wyk, 2019). Students exposed to a flipped classroom teaching strategy considerably increased their Biology achievement following the exposure, according to Adonu et al. (2021).

The preceding has demonstrated the high quality of research on the impact of a flipped classroom on student learning outcomes. The usefulness of the flipped classroom technique has been proven by various empirical evidence from the aforementioned studies. The majority of the research, however, focused on high school and university students rather than primary school students. Furthermore, none of the studies examined were conducted in Nigeria. As a result of these gaps in the literature, this empirical study on the use of flipped classrooms in primary schools in Nigeria was required. The goal of this study was to see how effective a flipped classroom educational technique is at improving children's Basic Science achievement in Nigeria. Thus, the research questions posed for this study were:

1. What are the mean achievement scores of children before (pretests) and after (posttests) exposure to flipped classroom instructional technique?

2. What are the moderating influences of gender, age and location on the achievement of children in Basic Science?

\section{Hypothesis}

Ho $_{1}$ : Flipped classroom instructional technique has no significant $(p<0.05)$ impact on children's Basic Science achievement.

$\mathbf{H o}_{2}$ : There are no significant influences of gender, age and location on the achievement of children in Basic Science. 


\section{Methods}

\subsection{Research design}

A simple repeated measures research design was used in this study. This design uses a single group of participants who are generally exposed to several test occasions prior to the start of treatment and subsequently subjected to various test occasions following treatment (Jones \& Kenward, 2003). The different test occasions in this example act as a control for the treatment condition. This design has recently been utilized in similar studies (Onyishi et al., 2021; Ugwuanyi, Ede, et al., 2020; Ugwuanyi, Gana, et al., 2020). The internal validity threats to this design include history of the participants' attributes, maturation, testing, instrumentation, statistical regression, selection of subjects, experimental mortality among others. On the other hand, the external validity threats to the design include interaction effect of testing, interaction effect of selection biases, reactive effects of experimental arrangement, multiple treatment interference among others.

\subsection{Participants}

This study enlisted the participation of 31 primary three children. The participants were selected from a population of primary three children in Nigeria's Enugu state. The study population figure as at the time of the research was 9,564 primary three children. Children with access to home technology, such as PCs and smartphones with internet capabilities, were chosen using a purposive sample technique. Purposive sampling technique was chosen to satisfy the intention of the researcher which was to use children who have access to internet and information technology (IT) gadgets.

Table 1 shows that the demographics of the participants differ significantly: $\chi^{2}=32.76, p<0.050$ (location of participants); $\chi^{2}=34.41, p<0.050$ (age of participants). However, the participants did not differ significantly by gender, $\chi^{2}=1.05, p>0.050$.

Table 1 Participants demographic characteristics

\begin{tabular}{lllll}
\hline $\begin{array}{l}\text { Demographics } \\
\text { characteristics }\end{array}$ & & $\mathrm{n}(\%)$ & $\chi^{2}$ & $p$ \\
\hline Location & Urban & 18(58.06) & 32.76 & $<.050$ \\
& Rural & $13(41.94)$ & & \\
Age & 6-7 Yrs & 24(77.42) & 34.41 & $<.050$ \\
& 8-9 Yrs & $6(19.35)$ & & \\
& $>9$ Yrs & $1(3.22)$ & & \\
Gender & Male & $15(48.39)$ & 1.05 & $>.050$ \\
& Female & $16(51.61)$ & & \\
\hline
\end{tabular}




\subsection{Measure}

The researcher's developed Basic Science Achievement Test (BSAT) was employed to collect information. The Basic Science concepts covered in the BSAT are concepts of air, liquid, communication, nutrition, measurement, simple machine, organs of the body, sound, planting of crop. The BSAT is a 30-item multiple-choice test with options $\mathrm{A}, \mathrm{B}$, and $\mathrm{C}$, with the children being expected to choose the proper answer for each question (see Appendix A). The BSAT questions were created using the primary three basic science scheme of work or curriculum. Any right answer received two marks, suggesting that the minimum and maximum scores were 0 and 60 , respectively. In other words, each of the 30 questions of the BSAT was awarded 2 marks when correctly answered and 0 when wrongly answered giving a total maximum mark of 60 and the lowest mark of 0 .

\subsection{Validation and reliability of the measure}

Test development experts at the researcher's institution validated the BSAT. The experts were asked to examine the BSAT items in terms of wording, fit for the research goal, quality, and language utilized. The BSAT was changed as a result of their validation decisions. Furthermore, the BSAT's content validation was ensured by a Table of requirements that was also evaluated by specialists. A table of specification is a two grid-table that shows the matching of the contents with the levels of cognitive domain according to Bloom's taxonomy of educational objectives. In the development of the 30-item BSAT, the researcher listed the topics covered as rows of the table and the level of cognitive domain as the column of the table. Thereafter percentage weights were assigned to each of the contents and the levels of the cognitive domain. Those percentage weights for each content as well as the level of cognitive domain gave rise to the number of BSAT items. That was done to ensure that the contents taught were adequately covered in the BSAT.

In order to determine the internal consistency reliability (pilot testing) of the BSAT, copies of the BSAT were given to a comparable sample of children in a different location to determine the items' reliability. The Kuder-Richardson formula 20 was used to analyze the data collected from such administration, yielding an internal consistency reliability index of 0.84 . By administering copies of the BSAT at two-week interval after the first administration, the temporal stability of the test was estimated. The data from the two administrations were analyzed using Pearson correlation, which yielded a 0.88 index.

\subsection{Procedure}

Before beginning the research, the researcher went to the schools that were used in the study to gain formal consent from the school headteachers. Informed consent papers were given to the parents as well as the teachers of the children who took part in the study to fill out and sign as evidence of their desire to participate. After completing all of these steps, the researcher planned baseline evaluations on two 
separate days. Those were conducted to ascertain the pretests measures (pretest 1 and pretest 2). The first administration (pretest 1) and second administration (pretest 2) had two weeks interval. Before the actual treatment began, the participants were given the BSAT items to respond to on two separate occasions. The pupils were given $40 \mathrm{~min}$ to respond to the BSAT items on each occasion. After that, the treatment began. Using a flipped classroom educational technique, the participants were exposed to a 6-week treatment condition. The concepts of air, liquid, communication, nutrition, measurement, simple machine, organs of the body, sound, planting of crop were among the Basic Science concepts to which the participants were exposed. The participants were given online materials on the concepts of air, liquid, communication, nutrition, measurement, simple machine, organs of the body, sound, planting of crop to study at home through an online platform, and then shared their experiences with the teacher as a moderator in the real classroom. This exercise lasted 6 weeks, following which the participants were given posttests on two separate occasions. The administration of posttest 1 and posttest 2 was done within an interval of two weeks. It is worth noting that the same contents of air, liquid, communication, nutrition, measurement, simple machine, organs of the body, sound, planting of crop were used to develop the BSAT which was used for both pretests and posttests. The only difference was that the items were reshuffled after each test without altering the contents.

\subsection{Ethical approval statement}

The University of Nigerian committee on research ethics provided ethical permission for the conduct of this study.

\subsection{Data analysis}

Mixed-design repeated measures analysis of variance was used to analyze data from the four separate test occasions. Specifically, mean and standard deviation were used to answer the research while the F-test of repeated measures analysis of variance was used to test the hypothesis. For the assumption of sphericity of repeated measures ANOVA, Mauchly's test of sphericity was not significant, Mauchly $W=0.859$, $p=0.502$. A repeated-measures ANOVA relies on the assumption of sphericity. It is the condition in which the variances of all conceivable pairings of within-subject conditions (i.e., levels of the independent variable) are identical.

Figure 1 is the schematic representation of the research methodology for this research. It shows at a glance the design of the study, participants, measure, test occasions, treatment and the method of data analysis.

\section{Results}

The results were presented in line with the research questions and hypotheses for the study. 


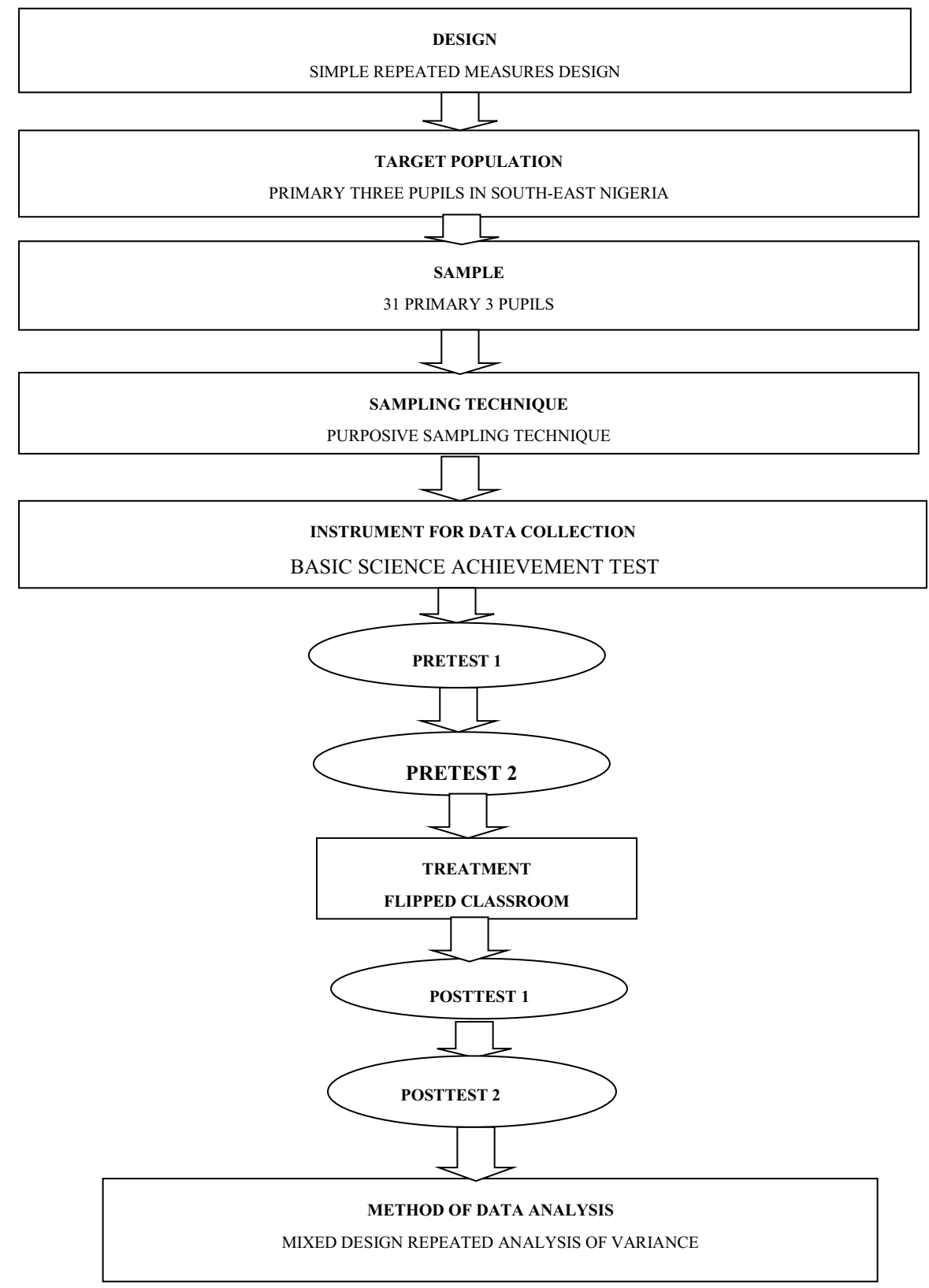

Fig. 1 Schematic Representation of the Methodology 
Table 2 Mean analysis of the achievement scores of the participants at four different test occasions

\begin{tabular}{llll}
\hline Test occasion & $\mathrm{n}$ & Mean & Std. Deviation \\
\hline Pretest 1 & 31 & 10.51 & 1.96 \\
Pretest 2 & 31 & 10.12 & 1.96 \\
Posttest 1 & 31 & 33.00 & 5.23 \\
Posttest 2 & 31 & 33.67 & 4.62 \\
\hline
\end{tabular}

Table 3 Repeated measures analysis of variance of the difference in the test occasions

\begin{tabular}{|c|c|c|c|c|c|c|c|}
\hline Source & & $\begin{array}{l}\text { Type III } \\
\text { Sum of } \\
\text { Squares }\end{array}$ & df & Mean Square & $\mathrm{F}$ & Sig & $\begin{array}{l}\text { Partial } \\
\text { Eta } \\
\text { Squared }\end{array}$ \\
\hline \multirow[t]{4}{*}{ Time } & Sphericity Assumed & $16,431.444$ & 3 & 5477.148 & 602.395 & .000 & .953 \\
\hline & Greenhouse-Geisser & $16,431.444$ & 1.590 & $10,334.831$ & 602.395 & .000 & .953 \\
\hline & Huynh-Feldt & $16,431.444$ & 1.664 & 9871.994 & 602.395 & .000 & .953 \\
\hline & Lower-bound & $16,431.444$ & 1.000 & $16,431.444$ & 602.395 & .000 & .953 \\
\hline \multirow[t]{4}{*}{ Error(Time) } & Sphericity Assumed & 818.306 & 90 & 9.092 & & & \\
\hline & Greenhouse-Geisser & 818.306 & 47.697 & 17.156 & & & \\
\hline & Huynh-Feldt & 818.306 & 49.934 & 16.388 & & & \\
\hline & Lower-bound & 818.306 & 30.000 & 27.277 & & & \\
\hline
\end{tabular}

Research Question One What are the mean achievement scores of children before (pretests) and after (posttests) exposure to flipped classroom instructional technique?

Table 2 reveals that the participants had mean achievement scores of $(M=10.51$, $S D=1.96$ and $M=10.12, \mathrm{SD}=1.96)$ at pretests 1 and 2 , respectively, and $(M=33.00, S D=5.23$ and $M=33.67, S D=4.62)$ at posttests 1 and 2 .

Ho: There is no significant difference in the mean achievement scores of children before (pretests) and after (posttests) exposure to flipped classroom instructional technique.

Table 3 demonstrated that flipped classroom had a substantial impact on the development of sound Basic Science knowledge, $F(3,90)=602.395, p<0.05$, $\eta_{p}{ }^{2}=0.953$. As a result, the effect size of 0.953 shows that the flipped classroom is responsible for a 95.3 percent change in the children's knowledge of Basic Science. Table 4 shows the post hoc pairwise comparison for the significant difference in the participants' mean scores at different test occasions. The mean difference between test 4 and test 1 contributed the most to the significant difference, according to Table 4, followed by the mean difference between test 4 and test 2 .

Research Question Two What are the moderating influences of gender, age and location on the achievement of children in Basic Science?

Table 5 showed that the correlation between children's achievement in basic science and their gender is 0.0967 implying that gender had very low influence on 
Table 4 Post-Hoc pairwise comparison test for the significant difference in the test occasions

\begin{tabular}{lllll}
\hline (I) Time & (J) Time & $\begin{array}{l}\text { Mean Differ- } \\
\text { ence (I-J) }\end{array}$ & Std. Error & Sig. \\
\hline 1 & 2 & .387 & .216 & .406 \\
& 3 & $-22.484^{*}$ & .961 & .000 \\
& 4 & $-23.161^{*}$ & .711 & .000 \\
2 & 1 & -.387 & .216 & .406 \\
& 3 & $-22.871^{*}$ & .988 & .000 \\
& 4 & $-23.548^{*}$ & .780 & .000 \\
3 & 1 & $22.484^{*}$ & .961 & .000 \\
& 2 & $22.871^{*}$ & .988 & .000 \\
& 4 & -.677 & .677 & .906 \\
4 & 4 & $23.161^{*}$ & .711 & .000 \\
& 1 & $23.548^{*}$ & .780 & .000 \\
& 2 & .677 & .677 & .906 \\
\hline
\end{tabular}

Table 5 Process analysis of the influence of the moderators

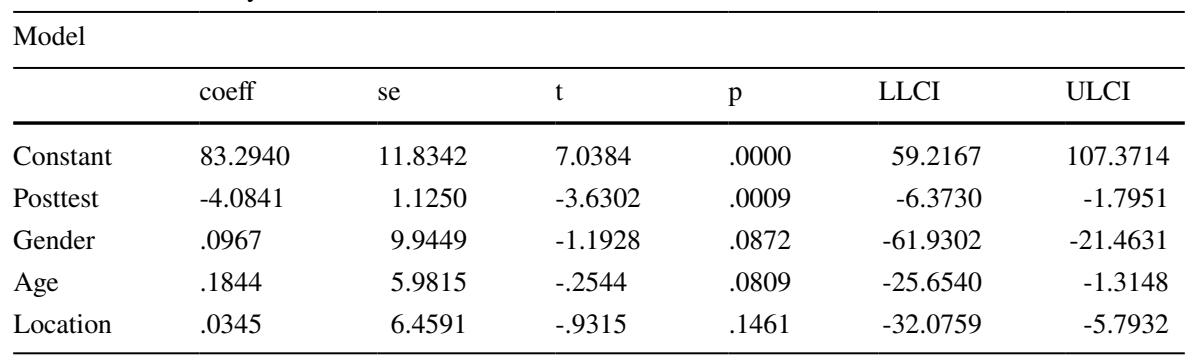

children's achievement. In the same way, the correlation between children's achievement and their age as well as location is 0.1844 and 0.0345 respectively. This means that while age had low influence on chilren's achievement, location had very low influence on their achievement.

$\mathbf{H o}_{2}$ : There are no significant influences of gender, age and location on the achievement of children in Basic Science.

Table 5 revealed that the moderators (gender, age, and participants' location) had no significant impacts on the effect of flipped classroom on the development of sound understanding of Basic Science topics by children, $t=-1.1938, p=0.0872$; $t=-0.2544, p=0.0809$; and $t=-0.9315, p=0.1461$.

\section{Discussion}

The purpose of this study was to see how the flipped classroom affected children's development of sound knowledge of Basic Science concepts. As a result of their exposure to a flipped classroom teaching technique, the children's development of good knowledge 
of Basic Science concepts improved dramatically over time, according to the study's findings. This demonstrated that students' achievement in Basic Science was greatly improved when they were taught using a flipped classroom. The findings also demonstrated that the demographic features of the participants (gender, age, and location) had no significant influences on the effect of the flipped classroom educational style. This finding indicates that the interactive character of the flipped classroom piques learners' interest in their ability to engage in such activities. In contrast to the traditional style of teaching, in which the teacher does everything, a flipped classroom is a learner-centered approach to teaching in which learners are provided resources to read or watch through an online platform. Pre-class exercises in a flipped classroom include textbook, webbased, or literature readings, as well as watching recordings of classroom lessons at their own leisure (Lichvar et al., 2016). As an innovative active learning strategy, flipped learning presents students with a variety of chances (Birgili et al., 2021). The findings of this study have been supported by a number of recent empirical studies.

When compared to other classroom models, teachers who used a flipped classroom dramatically improved children' academic attainment (Polat \& Karabatak, 2021). Children's performance and impressions of an online open distance-learning environment improved dramatically as a result of the flipped classroom strategy (Van Wyk, 2019). In a study of children's learning of science, those who were taught using the flipped classroom method performed much better than those who were taught using the standard lecture style (Joseph et al., 2021). As a result of the flipped learning outcomes, children's performance improved dramatically (Birgili et al., 2021). Children who took flipped courses improved their critical thinking skills substantially more than their peers who did not (Styers et al., 2018). Learning performance, motivation, as well as children's participation improved significantly once gaming components were introduced to a flipped classroom (Ekici, 2021). The implementation of a flipped classroom approach increased pupils' English language skills (Chang \& Lan, 2021). The use of a flipped classroom method has a considerable favorable influence on academic attainment in Science classes among children (Dogan et al., 2021). In a group of high school students, (Lichvar et al., 2016) discovered that using a flipped classroom is an effective and active learning technique.

This finding has a number of implications for science education. In the Nigerian context, it has been proven that the flipped classroom instructional approach improves children's achievement. This means that if teachers apply a flipped classroom instructional approach to teaching, science education in Nigeria will dramatically improve. Additionally, when students are introduced to the utilization of a flipped classroom approach, their interest and enthusiasm in learning science can be increased.

\section{Conclusion}

At the elementary school level, the flipped classroom approach is an effective instructional approach for teaching Basic Science. As a result, it is concluded that using a flipped classroom instructional strategy will considerably improve children's achievement in Basic Science. Teachers of Basic Science should embrace a flipped classroom educational strategy, especially in the COVID-19 
pandemic period, it is recommended. In addition, the Local Government Education Authority shall provide enough workshops/seminars to enable teachers to get the necessary skills in the usage of the flipped classroom.

\section{Appendix A}

\section{BASIC SCIENCE ACHIEVEMENT TEST (BSAT)}

Section A: Demographic Information of the Pupil

Instruction: Tick $(\sqrt{ })$ in the box that best describes you

Gender: Male

Age: 6-7 years

Location: Urban
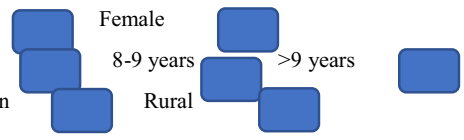

\section{Section B: BSAT QUESTIONS}

Instruction: Attempt all the questions

1. 1 . When air is moving, it is referred to as . (a) breeze, (b) hurricane (c) wind 2. dries our damp garments. (a) air (b) rain (c) dew

3. Air in motion is referred to as (a) wound (b) wind (c) winder.

4.___ refers to a method of communicating with others. (a) communication (b)

(b) contraction (c) conception

5. Wind's damaging impacts can communication devices. (a) repair

(b) retain (c) destroy

6. is a type of communication device. (a) telephone

(b) phony; (d) phonic

7. A colorless, odourless, or translucent liquid is referred to be Cola

8. A primary supply of water is . (a) stream (b) rain (c) pond

9. can be utilized in the kitchen to make a delicious meal

10. is a piece of school equipment.

(a) barometer (b) put on a dress

(c) use a spoon

11. Humans and animals can be weighed using a (a) meter rule

(b) weighing scale (c) thermometer

12. One of these is utilized to see small objects that our eyes are unable to see.

(a) manicoscrope (b) microscope (c) malicospose

13. The animal skeleton aids in the of human flesh. (a) finding (b) killing (c) support

14. All are all simple devices EXCEPT (a) stamp (b) scissors (c) fish

15. Working with will be difficult. (a) machine, (b) simple machine, and (c) generator

16. are organ we use in getting information around us (a) organ of the teeth (b) organ of the senses (c) organ of the mouth

17. How many sensory organs are there in our bodies?

(a) 5 (b) 6 (c) 7 
18.The organ fense for hearing is

(a) mouth (b) ear (c) teeth

19.The ability to see is known as

(a) environment (b) sight (c) objects

20.The orange in our face that we use for seeing things is called

(a) yes (b) ear (c) tongue

21. A cock (a) crows (b) moos (c) bleat

22. A bird (a) sings (b) barks (c) roars

23. is a sound made by man

(a) barks (b) talk (c) chimps

24. The sense organ for smelling is called (a) eye (b) nose (c) tongue

25. We use our nose to perceive both and

(a) pleasant and unpleasant smell (b) past and present (c) water and school smell

26. Water can be purified by it (a) boiling

(b) cooking

(c) draining

27. How many parts has a tooth? (a) 6 (b) 5 (c) 4

28. One of the following is not the condition for growing good crops (a) sunlight (b) chemical (c) moisture

29. and are examples of pest

(a) rats and snake (b) birds and rats

(c) lions and bats

30. An organism which significantly reduces the quality and quantity of crop plants is (a) pest (b) weed (c) disease

Acknowledgements The researcher is grateful to all of the research participants for their unwavering cooperation throughout the study.

\section{References}

Adonu, C. J., Nwagbo, C. R., Ugwuanyi, C. S., \& Okeke, I. O. (2021). Improving Students ' Achievement and Retention in Biology using Flipped Classroom and Powerpoint Instructional Approaches : Implication for Physics Teaching. International Journal of Psychosocial Rehabilitation, 25(2), 234247. https://doi.org/10.37200/IJPR/V25I2/PR320026

Afzali, Z., \& Izadpanah, S. (2021). The effect of the flipped classroom model on Iranian English foreign language learners: Engagement and motivation in English language grammar. Cogent Education, 8(1). https://doi.org/10.1080/2331186X.2020.1870801

Agboeze, M. U., Ugwuanyi, C. S., Okeke, C. I. O., Ugwu, G. C., Obikwelu, C. L., Obiozor, E. E., Oyigbo, D. N., \& Mbam, D. (2020). Matthias U. Agboeze, PhD. 34(June).

Birgili, B., Seggie, F. N., \& Ŏguz, E. (2021). The trends and outcomes of flipped learning research between 2012 and 2018: A descriptive content analysis. Journal of Computers in Education, 4. https://doi.org/10.1007/s40692-021-00183-y 
Chang, M. M., \& Lan, S. W. (2021). Flipping an EFL classroom with the LINE application: students' performance and perceptions. Journal of Computers in Education, 0123456789. https://doi.org/10. 1007/s40692-020-00179-0

Doğan, Y., Batdı, V., \& Yaşar, M. D. (2021). Effectiveness of flipped classroom practices in teaching of science : A mixed research synthesis. Research in Science \& Technological Education, 00(00), 1-29. https://doi.org/10.1080/02635143.2021.1909553

Ekici, M. (2021). A systematic review of the use of gamification in flipped learning. Education and Information Technologies. https://doi.org/10.1007/s10639-020-10394-y

Jones, B., \& Kenward, M. G. (2003). Design and Analysis of Cross-Over Trials (2nd ed.). Chapman and Hall.

Joseph, M. A., Roach, E. J., Natarajan, J., Karkada, S., \& Cayaban, A. R. R. (2021). Flipped classroom improves Omani nursing students performance and satisfaction in anatomy and physiology. $B M C$ Nursing, 20(1), 1-10. https://doi.org/10.1186/s12912-020-00515-w

Lichvar, A. B., Hedges, A., Benedict, N. J., \& Donihi, A. C. (2016). Combination of a flipped classroom format and a virtual patient case to enhance active learning in a required therapeutics course. American Journal of Pharmaceutical Education, 80(10), 1-8. https://doi.org/10.5688/ajpe8010175

Onyishi, C. N., Ede, M. O., Ossai, O. V., \& Ugwuanyi, C. S. (2021). Rational Emotive Occupational Health Coaching in the Management of Police Subjective Well-Being and Work Ability: A Case of Repeated Measures. Journal of Police and Criminal Psychology, 36(1), 96-111. https://doi.org/10. 1007/s11896-019-09357-y

Polat, H., \& Karabatak, S. (2021). Effect of flipped classroom model on academic achievement, academic satisfaction and general belongingness. Learning Environments Research, 0123456789. https://doi. org/10.1007/s10984-021-09355-0

Rotellar, C., \& Cain, J. (2016). Research, perspectives, and recommendations on implementing the flipped classroom. American Journal of Pharmaceutical Education, 80(2). https://doi.org/10.5688/ ajpe 80234

Styers, M. L., Van Zandt, P. A., \& Hayden, K. L. (2018). Active learning in flipped life science courses promotes development of critical thinking skills. CBE Life Sciences Education, 17(3), 1-13. https:// doi.org/10.1187/cbe.16-11-0332

Ugwuanyi, C. S., Ede, M. O., Onyishi, C. N., Ossai, O. V., Nwokenna, E. N., Obikwelu, L. C., Ikechukwu-Ilomuanya, A., Amoke, C. V., Okeke, A. O., Ene, C. U., Offordile, E. E., Ozoemena, L. C., \& Nweke, M. L. (2020a). Effect of cognitive-behavioral therapy with music therapy in reducing physics test anxiety among students as measured by generalized test anxiety scale. Medicine, 99(17), e16406. https://doi.org/10.1097/MD.0000000000016406

Ugwuanyi, C. S., Gana, C. S., Ugwuanyi, C. C., Ezenwa, D. N., Eya, N. M., Ene, C. U., Nwoye, N. M., Ncheke, D. C., Adene, F. M., Ede, M. O., Onyishi, C. N., \& Ossai, V. O. (2020). Efficacy of Cognitive Behaviour Therapy on Academic Procrastination Behaviours Among Students Enrolled in Physics, Chemistry and Mathematics Education (PCME). Journal of Rational - Emotive and Cognitive - Behavior Therapy, 0123456789. https://doi.org/10.1007/s10942-020-00350-7

Van Wyk, M. M. (2019). Flipping the Economics Class in a Teacher Education Course. Technology, Knowledge and Learning, 24(3), 373-399. https://doi.org/10.1007/s10758-018-9377-9

Publisher's note Springer Nature remains neutral with regard to jurisdictional claims in published maps and institutional affiliations. 